\title{
A Survival Analysis of Different Pulp Therapies in Decayed Primary Teeth
}

\author{
Aluhê Lopes-Fatturi1@, Juliana Feltrin de Souza²®, José Vitor Nogara Borges Menezes®, Fabian

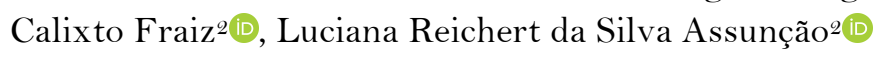

${ }^{1}$ Post-Graduate Program in Dentistry, Department of Stomatology, School of Dentistry, Federal University of Paraná, Curitiba, PR, Brazil.

2Department of Stomatology, School of Dentistry, Federal University of Paraná, Curitiba, PR, Brazil.

Author to whom correspondence should be addressed: Luciana Reichert da Silva Assunção, Avenida Prefeito Lothário Meissner, 632, Curitiba, PR, Brazil.80210-170. Phone: +554133604025. E-mail: lurassuncao@yahoo.com.br.

Academic Editors: Alessandro Leite Cavalcanti and Wilton Wilney Nascimento Padilha

Received: 16 June 2019 / Accepted: 20 January 2020 / Published: 24 February 2020

How to cite this article: Lopes-Fatturi A, de Souza JF, Menezes JVNB, Fraiz FC, Assunção LRS. A survival analysis of different pulp therapies in decayed primary teeth. Pesqui Bras Odontopediatria Clín Integr. 2020; $20: e 4822$. https://doi.org/10.1590/pboci.2020.038

\begin{abstract}
Objective: To identify the clinical and radiographic conditions associated with failure of pulp therapy in primary teeth through a survival analysis. Material and Methods: A total of 1000 records of children assisted at the pediatric dentistry clinic of the Federal University of Parana, Brazil, from the years 2000 to 2010, were analyzed. The mean evaluation time was 10.61 months (minimum/maximum: 1/28) from the report of pulp therapy. The different types of treatments analyzed included indirect pulp treatment (IPT), direct pulp treatment (DPT), pulpotomy and pulpectomy. The Kaplan-Meyer method and log-rank test were used for the survival analysis. Exodontia was considered as the outcome variable and censors included: traumatic tooth loss, presence of the tooth in the oral cavity and physiologic tooth exfoliation. Results: A total of 122 records reporting pulp therapy in the primary teeth were selected. From this, 16 teeth (13.12\%) were extracted. Survival analysis showed that pulpectomy presented lower survival rates when compared to conservative therapies $(\mathrm{p}=0.0297)$. Teeth with furcal lesions and pathological root resorption before pulp therapy had lower survival rates when compared to those that did not present these conditions $(\mathrm{P}=0.006)$. Presence of fistula and abscess after pulp therapy were also associated with lower survival rates $(\mathrm{P}=0.0062$ and 0.0143 , respectively). Conclusion: Signals of pulp necrosis were associated to lower survival rates in primary teeth submitted to pulp therapy.
\end{abstract}

Keywords: Root Canal Therapy; Tooth, Primary; Survival Analysis. 


\section{Introduction}

Despite advances in oral health promotion, dental caries affecting primary teeth is still prevalent and remains a challenge for oral health professionals. The global burden of disease study, which includes three independent systematic reviews reveals that oral health has not improved in the last 25 years and the rate of untreated caries in primary teeth was 8.2 in 1990 and 7.8 in 2015[1]. A cohort study with 163 Brazilian children aged three to four years old showed that caries progression can have a negative impact on oral healthrelated quality of life [2].

Pulp therapy plays a major role in preserving primary tooth affected with dental caries [3]. The choice of the appropriate approach depends on the diagnostic of the pulp condition based on clinical examination and radiographic findings. Clinically, symptoms such as thermal or periapical sensitivity, edema and pain are observed. In the radiographic examination, evidence of internal or external resorption of the root, periapical or inter-radicular radiolucent areas, irregular root calcification or incomplete root formation are evaluated [4]. Actual recommendations, supported by evidence-based dentistry, indicate less invasive carious lesions management [5]. The partial removal of carious tissues prioritizes preserving healthy and remineralize tissues to maintain pulpal health and to avoid restorative cycle [6]. A randomized controlled trial using conebeam computed tomography conducted on 94 children aged 7-12 years showed success rates on 57 primary molar teeth submitted to indirect pulp therapy. After 1 year of follow-up, there was a good prognosis in $96.8 \%$ teeth according to the clinical criteria of the American Academy of Pediatric Dentistry [7].

A total of 42 primary first molars in children 4 to 7 years of age with a history of spontaneous pain, mobility and furcation and periapical lesion as radiographic signal were submitted to endodontic therapy. The material used was calcium hydroxide and an iodoform base. A success rate of $85.7 \%$ was observed defined as an absence of symptoms and pathological radiographic signs, with clinical and radiographic follow-up of 6 months [8].

Some recent studies identified factors related to failure rate in pulp therapies as a result of carious lesions through a survival analysis [9]. A study that aimed to evaluate the survival rates of indirect pulp therapy compared to two different pulpotomy medicaments, formocresol and ferric sulfate, was conducted in primary molars. After three-years follow up, indirect pulp therapy had 96.2\% of survival rate, formocresol pulpotomy had a $65 \%$ survival rate and pulpotomy with ferric sulfate, $62.9 \%$ survival rate [10]. The survival probability of partial caries removal was verified in 284 cases with high caries experience. Previous restorative treatment in anterior teeth, restorative failures and teeth with visible plaque were related to failure [11].

This study aimed to evaluate clinical and radiographic conditions that interfere in the survival of primary teeth submitted to different types of pulp therapies using a survival analysis. The results of this research will allow a possible prediction of the prognosis of the primary tooth in relation to some specific clinical and radiographic conditions.

\section{Material and Methods}

Study Design and Sample

This is a retrospective cohort study. All dental records of children aged 4 to 11 years old between 2000 and 2010 at the Pediatric Dentistry Clinic of the Federal University of Paraná, Curitiba, Brazil, were analyzed, totaling 1000 records. Only those with a history of pulp therapy in primary teeth due to carious involvement were selected. The different types of treatments analyzed included indirect pulp treatment (IPT), direct pulp treatment (DPT), pulpotomy and pulpectomy. The evaluation unit was the tooth. If a child had 
more than one tooth undergoing pulp therapy, all teeth were included in the analysis. Incomplete dental records or teeth with radiographic images that made proper radiographic analysis impossible were excluded. Clinical aspects such as the presence of spontaneous pain, abscess or fistula, were obtained through information contained in the patient's records.

The choice of the type of treatment followed the protocol for pulp therapies in primary teeth of the Pediatric Dentistry Department of the Federal University of Paraná based on the guidelines of the American Dental Association's Guidelines on Pulp Therapy for Primary and Immature Permanent Teeth [12]. Indirect pulp capping was performed on teeth with no clinical signs and symptoms of pulp necrosis or irreversible pulpitis. The affected dentin tissue was maintained, and a thin layer of calcium hydroxide cement was applied over the remaining tissue. The cavity was restored with glass ionomer cement. The direct pulp capping is indicated in teeth with clinical and radiographic signs that indicate pulp vitality and pulp exposure. The pulp exposure site was protected with calcium hydroxide cement and the teeth restored with glass ionomer cement. Pulpotomy was performed in cases of pulp exposure with presence of caries affected dentin, with formocresol being the substance of choice. In primary teeth with necrotic pulp tissue or irreversible pulpitis, pulpectomy was the procedure of choice. The root canals were debrided and irrigated with one percent sodium hypochlorite for disinfection. Instrumentation of the root was performed by subtracting $2 \mathrm{~mm}$ of the radiographic root length. After the canals were dried, a iodoform-based paste (Pasta de Guedes)[13] was used to fill the canals. The tooth was restored with a temporary restoration with zinc/oxide eugenol. The root canal was filled with a calcium hydroxide and iodoform based paste Teeth with signs of necrosis (i.e. abscess fistula and / or pathological resorption less than $2 / 3$ of the root) were submitted to a new endodontic treatment. All clinical procedures involving pulp therapy in primary teeth were performed in one session, under local anesthesia and with the use of a rubber dam. The clinical procedures were performed by undergraduate students of the dentistry course of the Universidade Federal do Paraná. All the students received theoretical training prior to the execution of the procedures and were supervised during all stages by one of the researchers (JVNBM).

\section{Data Collection}

After the selection of the patient's records, aspects such as the age of the patient at the time of pulp therapy, gender, modality of pulp therapy were evaluated. The following clinical characteristics were observed before and after pulp therapy: presence of pain, abscess or fistula associated with the treated tooth. The radiographic characteristics observed before and after pulp therapy were: presence of radiolucent lesion in the periapical or furcation area, presence of radiographic signs of pathological root resorption and degree of rhizolysis (1/3 or $2 / 3$ of the root). Clinical and radiographic conditions prior to pulp therapy included any reports in the dental record immediately prior to the completion of pulpal therapy. Analysis of clinical conditions following pulp therapy included reporting within the study period or immediately prior to the completion of the exodontia when necessary. The last radiographic examination was considered to be performed within the study period or just before the exodontia.

For the statistical analysis, the age of the child at the moment of the pulp therapy was categorized according to the median value in: $\leq 7$ years and $>7$ years. The type of pulp therapy was categorized as conservative (including indirect pulp treatment, direct pulp treatment and pulpotomy) and non-conservative (pulpectomy). The type of material used was categorized into: calcium hydroxide, formocresol and iodoform pastes. Survival analysis was performed using the Kaplan-Meier method and survival curves were assessed by the log-rank test. It was considered as a reference category situation that could contribute to the longer time of 
permanence of the dental element in the oral cavity. Exodontia of the tooth as a consequence of pulp therapy failure was considered as a failure. The censored observations were considered when there was a loss of the element due to dental trauma, teeth that remained in the oral cavity until the end of the study and natural exfoliation of the tooth. The mean evaluation time was 10.61 months (minimum/maximum:1/28) from the report of pulp therapy.

\section{Data Analysis}

Univariate and multivariate analysis were performed using Cox proportional hazards regression method to estimate the hazard ratios and the respective confidence interval. A stepwise forward selection model was used. All independent variables with $\mathrm{p}<0.20$ in the univariate analysis were selected and those which were significant $(\mathrm{p}<0.05)$ were kept in the final model after being fitted. The data were performed by the STATA program version 12.0 (College Station, TX, USA). The level of significance adopted for the analyzes was $5 \%$.

Ethical Aspects

This study was carried out after approval by the Human Research Ethics Committee of the Federal University of Paraná (UFPR) (Process No. 50017115.9.0000.0102). The present study was conducted in accordance with the Helsinki Declaration (2008). Permission to collect patient data was obtained by an informed consent signed by the children's guardian before treatment.

\section{Results}

From the 1000 dental records evaluated, 125 were selected with reports of pulp therapy. Three dental records were excluded due to the poor quality of the radiographic images, totaling 122 records to be analyzed. Each dental record showed only one primary tooth submitted to pulp therapy, totaling 122 teeth. A total of 38 teeth $(31.2 \%)$ were submitted to indirect pulp capping 16, (13.1\%) direct pulp capping, 11 (9\%) pulpotomy and $57(46.7 \%)$ pulpectomy (Figure 1).

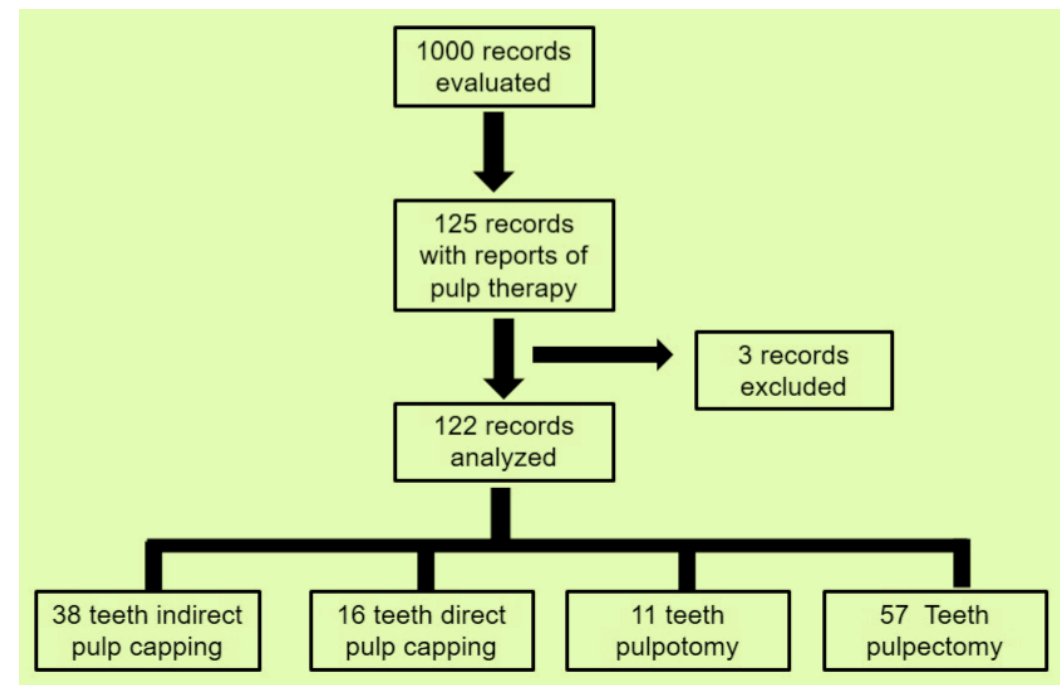

Figure 1. Fluxogram of the records. 
Sixty-four records were from female patients (52.5\%). The mean age was 7.2 years, minimum 4 years and maximum 11 years. Of the evaluated teeth, 17 (13.9\%) were incisors, $46(37.7 \%)$ first molars, 57 (46.7\%) second molars and only two canines (1.7\%). The total time of evaluation of the study was 28 months.

Of the 122 teeth evaluated, $16(13.2 \%)$ were submitted to exodontia, 28 (22.9\%) exfoliated naturally and $78(63.9 \%)$ were still present in the oral cavity at the end of the study period. There was no loss due to trauma and no case of endodontic retreatment. $14(87.5 \%)$ of the 16 teeth had a premature loss. Exodontia was performed within a period of 10 months. Regarding the type of pulp therapy, two teeth were submitted to direct pulp therapy, three to pulpotomy and twelve to pulpectomy. There was no history of exodontia in cases of indirect pulp therapy. In relation to the tooth, $14(87.5 \%)$ were primary molars and $2(12.5 \%)$ were incisors.

Teeth submitted to pulpectomy had a lower survival rate when compared to teeth submitted to more conservative therapies, as shown on Table 1.

Table 1. Survey analysis of teeth submitted to pulp therapy according to child's age, type of therapy, type of material used and teeth group.

\begin{tabular}{lccccc}
\hline \multicolumn{1}{c}{ Variables } & N (\%) & $\begin{array}{c}\text { Failures } \\
\text { N (\%) }\end{array}$ & $\begin{array}{c}\text { Mean for Survival } \\
\text { Time CI (95\%) }\end{array}$ & $\begin{array}{c}\text { Survival Rate } \\
\text { (in \%) }\end{array}$ & p-value \\
\hline $\begin{array}{l}\text { Age (in Years) } \\
\leq 7\end{array}$ & $63(51.64)$ & $8(6.56)$ & $24.53(22.30-26.76)$ & 85.56 & 0.6505 \\
$\quad 57(48.36)$ & $8(6.56)$ & $22.71(20.70-25.35)$ & 54.76 & \\
$\quad \begin{array}{l}\text { Type of Therapy } \\
\quad \text { Conservative }\end{array}$ & $65(53.28)$ & $5(4.10)$ & $27.00(25.63-28.36)$ & 81.28 & $\mathbf{0 . 0 2 9 7}$ \\
$\quad$ Radical & $57(46.72)$ & $11(9.02)$ & $20.95(18.23-23.67)$ & 74.43 & \\
Group of Teeth & & & & \\
$\quad$ Incisors and Canines & $19(15.57)$ & $2(1.64)$ & $25.16(21.43-28.88)$ & 88.24 & 0.5678 \\
$\quad \begin{array}{l}\text { First Molars } \\
\text { Second Molars }\end{array}$ & $46(37.71)$ & $8(6.56)$ & $22.37(19.45-25.29)$ & 78.51 & \\
\hline
\end{tabular}

$\neq$ Log-rank test; Failures were considered as the exodontia of the tooth; $\mathrm{CI}=$ Confidence Interval; Significant values marked in bold.

Radiographic findings of furcation lesions and pathological root resorption before pulp treatment were associated with a lower survival rate when compared to teeth that did not present these radiographic findings. The survival rate was also inversely proportional to the degree of pathological root resorption, i.e., the higher the degree of pathological root resorption of the affected tooth before pulp therapy the lower was the survival rate (Table 2 ).

Table 2. Survey analysis of teeth submitted to pulp therapy according to clinical and radiographic factors before pulp therapy.

\begin{tabular}{|c|c|c|c|c|c|}
\hline Variables & $\mathbf{N}(\%)$ & $\begin{array}{c}\text { Failures } \\
\text { N (\%) }\end{array}$ & $\begin{array}{l}\text { Mean for survival } \\
\text { time CI }(95 \%)\end{array}$ & $\begin{array}{l}\text { Survival Rate } \\
\text { (in \%) }\end{array}$ & p-value \\
\hline \multicolumn{6}{|l|}{ Pain } \\
\hline Yes & $12(9.84)$ & $3(2.46)$ & $15.40(10.39-20.41)$ & 57.29 & 0.3935 \\
\hline No & $5(4.10)$ & $2(1.64)$ & $9.75(4.60-14.91)$ & 50.00 & \\
\hline \multicolumn{6}{|l|}{ Fistula } \\
\hline Yes & $13(10.66)$ & $5(4.10)$ & $17.26(10.89-23.63)$ & 52.75 & 0.2382 \\
\hline No & $4(3.28)$ & $\mathrm{o}(0.0)$ & **⿻丷木 & 100 & \\
\hline \multicolumn{6}{|l|}{ Abscess } \\
\hline Yes & $8(6.56)$ & $4(3.28)$ & $10.70(6.47-14.93)$ & 36.46 & 0.1626 \\
\hline No & $5(4.10)$ & $\mathrm{o}(0.0)$ & **⿻丷木 & 100 & \\
\hline \multicolumn{6}{|l|}{ Furcal Lesion } \\
\hline Yes & $45(36.89)$ & $11(9.02)$ & $20.36(17.10-23.62)$ & 48.11 & 0.0065 \\
\hline No & $58(47.54)$ & $3(2.46)$ & $23.70(22.27-25.12)$ & 92.32 & \\
\hline
\end{tabular}


Periapical Lesion

$\begin{array}{cccccc}\text { Yes } & 8(6.56) & 2(1.64) & 10.00(6.40-13.60) & 75.00 & 0.0879 \\ \text { No } & 11(9.02) & 0(0.0) & * * & 100 & \end{array}$

Pathological Root Resorption

$\begin{array}{lccccc}\text { Yes } & 46(37.71) & 11(9.02) & 20.58(17.35-23.82) & 69.71 & \mathbf{0 . 0 0 4 0} \\ \text { No } & 76(62.29) & 5(4.10) & 26.00(24.32-27.67) & 80.20 \\ \text { egree of Rhizolysis } & & & & 0.0006 \\ \text { No Reabsorption } & 75(61.48) & 5(4.10) & 25.97(24.27-27.66) & 80.11 & 81.62 \\ \text { Up to 1/3 Root } & 28(22.95) & 4(3.28) & 23.13(19.67-26.58) & 54.04 \\ \text { Up to 2/3 Root } & 19(15.57) & 7(5.74) & 13.98(9.97-17.98) & \mathbf{0 . 0 4}\end{array}$

*Values less than 122 are due to lack of data for this variable; łLog-rank test; Failures were considered as the exodontia of the tooth; Significant values marked in bold; **Mean for survival time not computed because all cases are censored.

Figures 2 and 3 show the survival curves in the total sample and stratified by pulpotomy and pulpectomy, respectively. Although the number of teeth undergoing extraction was higher in the pulpectomy therapy group $(n=11)$ compared to the pulpotomy therapy group $(n=3)$, the difference was not significant (logrank test; $\mathrm{p}=0.7155)$.

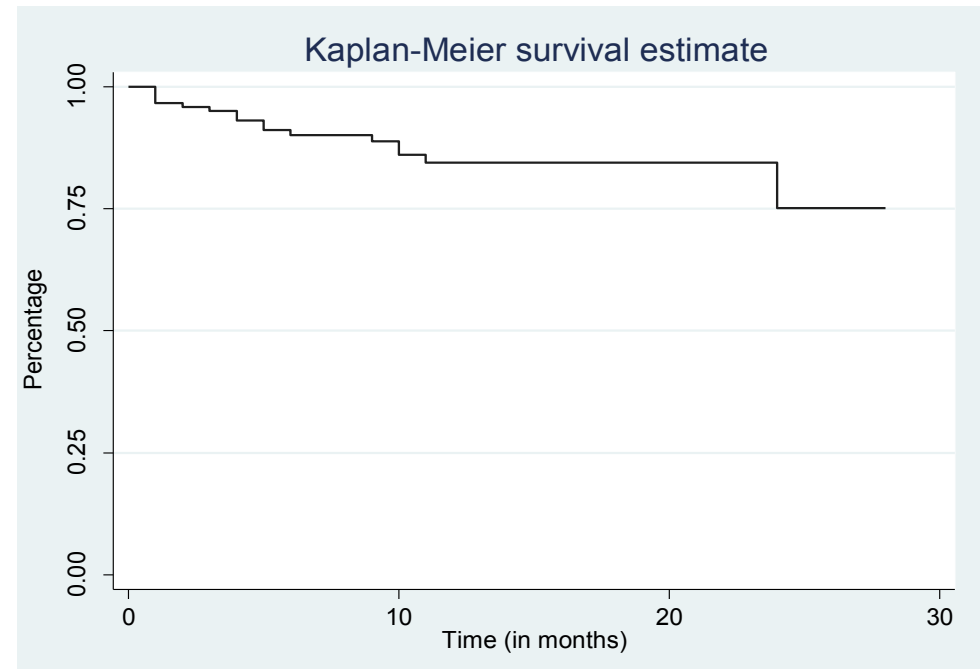

Figure 2. Survival curve associated with failure of pulp therapy in the total sample.

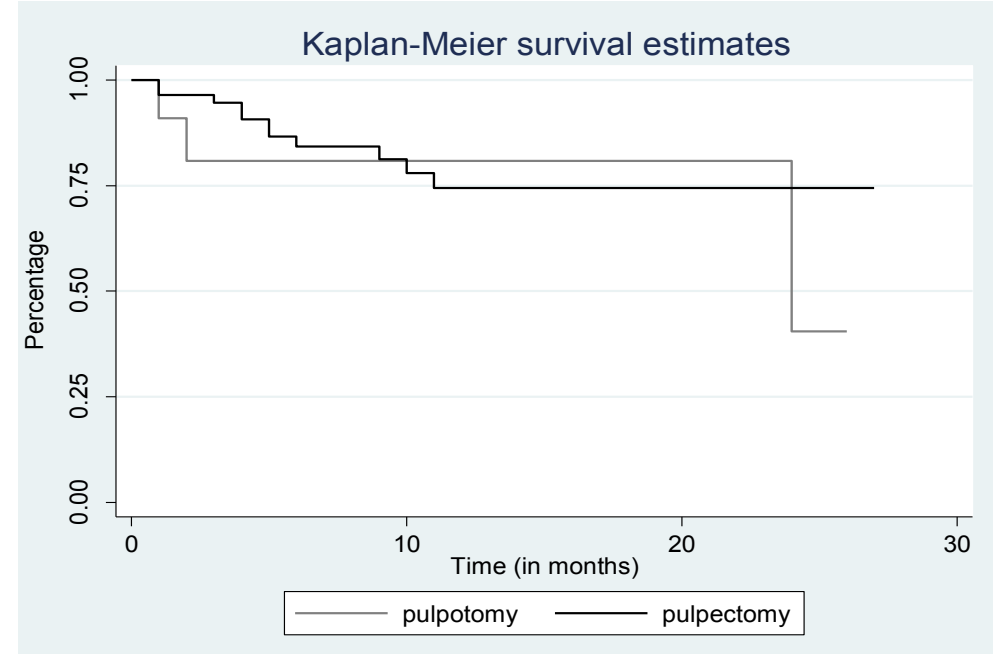

Figure 3. Survival curve associated with failure of pulp therapy in primary teeth stratified by pulpotomy and pulpectomy. 
Table 3 shows the survival analysis of teeth submitted to pulp therapy according to the clinical and radiographic findings after treatment. Only four cases reported a history of pain in the dental records, making it impossible to analyze possible associations with this variable. Presence of fistula and abscess after treatment had a lower survival rate when compared to teeth that did not present these events. Similarly, furcation lesion and pathological root resorption after pulp therapy also presented a lower survival rate when compared to the elements that did not present these radiographic findings. The degree of pathological root resorption after pulp therapy also influenced the survival rate.

Table 3. Survey analysis of teeth submitted to pulp therapy according to clinical and radiographic factors after pulp therapy.

\begin{tabular}{|c|c|c|c|c|c|}
\hline Variables & $\mathbf{N}(\%)$ & $\begin{array}{c}\text { Failures } \\
\text { N (\%) }\end{array}$ & $\begin{array}{c}\text { Mean for survival } \\
\text { time CI }(95 \%)\end{array}$ & $\begin{array}{l}\text { Survival Rate } \\
\text { (in \%) }\end{array}$ & p-value \\
\hline Fistula & & & & & 0.0062 \\
\hline Yes & $16(13.12)$ & $4(3.28)$ & $20.19(14.66-25.72)$ & o & \\
\hline No & $1(0.82)$ & $1(0.82)$ & $1.00(1.00-1.00)$ & 65.48 & \\
\hline \multicolumn{6}{|l|}{ Abscess } \\
\hline Yes & $13(10.66)$ & $4(3.28)$ & $12.42(8.96-15.88)$ & $\mathrm{O}$ & 0.0143 \\
\hline No & $1(0.82)$ & $1(0.82)$ & $1.00(1.00-1.00)$ & 51.28 & \\
\hline \multicolumn{6}{|l|}{ Furcal Lesion } \\
\hline Yes & $44(36.07)$ & $11(9.02)$ & $20.19(16.85-23.52)$ & 47.50 & 0.0046 \\
\hline No & $59(48.36)$ & $3(2.46)$ & $23.73(22.33-25.12)$ & 92.52 & \\
\hline \multicolumn{6}{|l|}{ Periapical Lesion } \\
\hline Yes & $8(6.56)$ & $2(1.64)$ & $10.00(6.40-13.60)$ & 75.00 & 0.0879 \\
\hline No & $11(9.02)$ & $0(0.0)$ & *** & 100 & \\
\hline \multicolumn{6}{|c|}{ Pathological Root Resorption } \\
\hline Yes & $49(40.16)$ & $12(9.84)$ & $20.44(17.28-23.59)$ & 69,04 & 0.0014 \\
\hline No & $73(59.84)$ & $4(3.28)$ & $26.30(24.71-27.89)$ & 81.38 & \\
\hline \multicolumn{6}{|l|}{ Degree of Rhizolysis } \\
\hline No Reabsorption & $71(58.20)$ & $3(2.46)$ & $26.65(25.19-28.11)$ & 82.49 & 0.0006 \\
\hline Up to $1 / 3$ Root & $30(24.59)$ & $6(4.92)$ & $21.43(17.52-25.34)$ & 74.39 & \\
\hline Up to $2 / 3$ Root & $21(17.21)$ & $7(5.74)$ & $17.82(12.99-22.65)$ & 59.93 & \\
\hline
\end{tabular}

*Values less than 122 are due to lack of data for this variable; łLog-rank test, Failures were considered as the exodontia of the tooth; Significant values marked in bold; **Mean for survival time not computed because all cases are censored.

Table 4 shows the results of Cox's proportional-hazards regression. Radical therapies had a 6.93greater risk of extraction compared to more conservative therapies. Regarding clinical or radiographic characteristics before pulp therapy, teeth with furcal lesion, pathological root resorption, or up to $2 / 3$ degree of rhizolysis were at higher risk of failure after pulp therapy. Similarly, teeth with furcal lesions, pathological root resorption, or up to $2 / 3$ degree of rhizolysis after pulp therapies were at higher risk for extraction due to pulp therapy failure. No variable remained independent associated with pulp therapy failure in the multivariate analysis.

Table 4. Cox's proportional-hazards regression associated with failure of pulp therapy and the interested variables.

\begin{tabular}{lcc}
\hline Variables & HR (95\%CI) & p-value \\
\hline $\begin{array}{c}\text { Type of Therapy } \\
\text { Conservative }\end{array}$ & Ref. & \\
Radical & $6.93(1.57-30.71)$ & $\mathbf{0 . 0 1 1}$ \\
$\begin{array}{l}\text { Before Pulp Therapy } \\
\text { Furcal Lesion }\end{array}$ & &
\end{tabular}




\begin{tabular}{|c|c|c|}
\hline No & Ref. & \\
\hline Yes & $4.96(1.38-17.38)$ & 0.014 \\
\hline \multicolumn{3}{|c|}{ Pathological Root Resorption } \\
\hline No & Ref. & \\
\hline Yes & $4.17(1.44-12.04)$ & 0.008 \\
\hline \multicolumn{3}{|l|}{ Degree of Rhizolysis } \\
\hline No Reabsorption & Ref. & \\
\hline Up To 1/3 Root & $2.27(0.61-8.47)$ & 0.221 \\
\hline Up To $2 / 3$ Root & $7.30(2.25-23.79)$ & 0.001 \\
\hline \multicolumn{3}{|l|}{ After Pulp Therapy } \\
\hline \multicolumn{3}{|l|}{ Fistula } \\
\hline No & Ref. & \\
\hline Yes & $16.00(1.07-255.80)$ & 0.050 \\
\hline \multicolumn{3}{|l|}{ Abscess } \\
\hline No & Ref. & \\
\hline Yes & $13.00(0.81-207.84)$ & 0.070 \\
\hline \multicolumn{3}{|l|}{ Furcal Lesion } \\
\hline No & Ref. & \\
\hline Yes & $5.26(1.46-18.96)$ & 0.011 \\
\hline \multicolumn{3}{|c|}{ Pathological Root Resorption } \\
\hline No & Ref. & \\
\hline Yes & $5.21(1.67-16.24)$ & 0.004 \\
\hline \multicolumn{3}{|l|}{ Degree of Rhizolysis } \\
\hline No Reabsorption & Ref. & \\
\hline Up To 1/3 Root & $5.87(1.46-23.64)$ & 0.013 \\
\hline Up To $2 / 3$ Root & $9.39(2.42-36.44)$ & 0.001 \\
\hline
\end{tabular}

\section{Discussion}

Of the different types of pulp therapies evaluated in this study, pulpectomy was associated with a lower survival rate when compared to more conservative pulp therapies such as direct and indirect pulp capping and pulpotomies. Pulpectomy-treated teeth had a 6.93 higher risk of failure when compared to more conservative therapies. This fact refers to the treatment itself, which presents numerous challenges for its execution. For the pulpectomy to have a favorable clinical and radiographic prognosis, effective cleaning of the root canals and removal of the bacteria and their by-products. However, the complex anatomy of the root canals of the primary teeth compromises their adequate cleaning, leaving remaining microorganisms and necrotic pulp tissue, leading to the development of pathological root resorption, contributing to the failure of this type of treatment [14,15].

In the case of therapies considered more conservative in the primary teeth with pulp vitality, five of the 16 teeth with premature loss were submitted to direct pulp capping or pulpotomy. There was no history of unsuccessful in cases of indirect pulp capping within the evaluation period. This is an interesting result since, of the 122 teeth submitted to pulp therapy, 38 (31.2\%) were submitted to indirect pulp capping. In a recent systematic review and meta-analysis, where success rates for indirect pulp protection, direct pulp protection and pulpotomy were evaluated, indirect pulpal protection was associated with a success rate of $94.4 \%$ over a 24-hour period month of evaluation [16].

Considering the clinical and radiographic conditions associated with failure, teeth that presented radiographically furcal lesion before pulp therapy had a lower survival rate when compared to teeth that did not present this condition ( $\mathrm{HR}=4.96$; CI95\%: 1.38-17.38; $\mathrm{p}=0.014)$. The presence of radiographic signs 
indicating pulp necrosis, such as lesions and pathological root resorption before pulp treatment may interfere directly or indirectly with the repair process after pulp treatment [17]. In a study of 348 primary teeth, signs of pathological resorption and furcal lesions prior to treatment were associated with an unfavorable prognosis for successful pulp therapy [18]. The success in the pulp treatment of teeth without furcation lesions was $100 \%$ versus $84 \%$ in those who had this radiographic condition [19].

Likewise, teeth that presented radiographically furcal lesions after pulp therapy also showed a lower survival rate when compared to those without this condition $(\mathrm{HR}=5.26$; CI95\%: 1.46-18.96; $\mathrm{p}=0.011)$. The presence of bacteria plays an important role in the onset, progression and persistence of apical lesions, because bacteria in infected root canals and peri-root tissues can invade and reside within the dentin and cement surrounding areas, thus the microorganisms can remain viable even after the biomechanical preparation and irrigation of the root canal system of the primary teeth [20]. In addition to these aspects, the radiographic evolution with elimination or reduction of rarefaction area is suggestive of a successful endodontic therapy $[21]$.

The degree of rhizolysis before pulp therapy was also an aspect that was associated with the survival rate of primary teeth submitted to pulp therapy. Although the recommendation of the American Academy of Pediatric Dentistry is that endodontic treatment be performed on primary teeth with pathological root resorption of a maximum of $1 / 3$ root length [12], in $15.6 \%$ of cases pulp therapy was performed with $2 / 3$ pathological root resorption with the intention of maintaining the tooth in the oral cavity for a period close to its physiological exfoliation. In conditions in which the teeth present up to half of the root, the endodontic treatment is able to maintain it in healthy conditions in the oral cavity [17].

All teeth that had abscesses and fistulas after endodontic treatment were lost early. The presence of fistulas and abscesses are signs of infectious processes and the non-regression of these clinical characteristics can occur due to the persistence of microorganisms in the root canals after its chemical and mechanical preparation, which can lead to a new infection, thus disfavoring the prognosis of pulp therapies [22]. In the Cox proportional hazards regression, these variables had borderline significance, probably because of the small sample size.

Although the results of this study showed a lower survival of teeth submitted to radical root canal treatment, the indication of this therapy is justified by the possibility of maintenance of the primary tooth in the oral cavity in healthy and non-pathological conditions until its exfoliation. Early loss of the primary tooth can lead to loss of space, phonetic problems and negatively impact the quality of life of children due to unfavorable aesthetics, impaired eating that can lead to nutritional problems, changes in speech development, and contribute to establish harmful habits and integrity of dental arches [23,24].

Because of the relatively small sample size, the multivariate analysis showed that no variables were independently associated with failure after pulp therapies. Therefore, it is suggested that this is an important aspect and needs further investigation, using a larger sample, allowing more accurate data and reducing false negative results.

\section{Conclusion}

The results of this study showed that pulpectomies, clinical and radiographic signs of pulpal necrosis as well as the degree of rhizolysis were associated with a lower survival rate. These data emphasize the importance of well-defined strategies for the preservation of primary teeth submitted to pulp therapy. 


\section{Authors' Contributions}

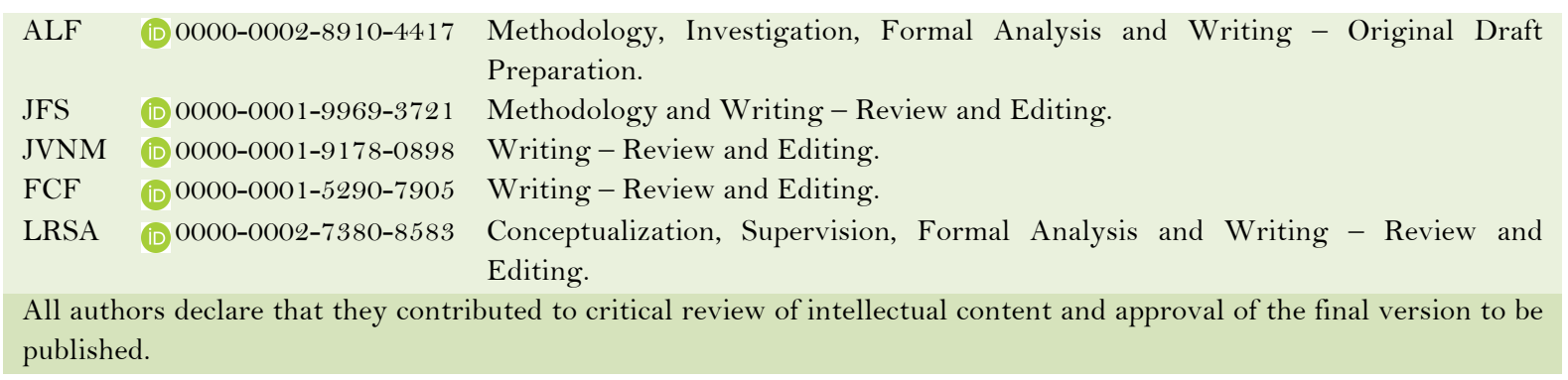

\section{Financial Support}

None.

\section{Conflict of Interest}

The authors declare no conflicts of interest.

\section{References}

[1] Kassebaum NJ, Smith AGC, Bernabe E, Fleming TD, Reynolds AE, Vos T, et al. Global, regional, and national prevalence, incidence, and disability-adjusted life years for oral conditions for 195 countries, 1990-2015: a systematic analysis for the global burden of diseases, injuries, and risk factors. J Dent Res 2017; 96(4):380-7. https://doi.org/10.1177/0022034517693566

[2] Piva F, Pereira JT, Luz PB, Hugo FN, de Araujo FB. Caries progression as a risk factor for increase in the negative impact on OHRQOL - a longitudinal study. Clin Oral Investig 2018; 22(2):819-28.

https://doi.org/10.1007/s00784-017-2 157-4

[3] Godhi B, Tyagi R. Success rate of MTA pulpotomy on vital pulp of primary molars: a 3-year observational study. Int J Clin Pediatr Dent 2016; 9(3):222-7. https://doi.org/10.5005/jp-journals-10005-1368

[4] Rodd HD, Waterhouse PJ, Fuks AB, Fayle SA, Moffat MA, British Society of Paediatric Dentistry. Pulp therapy for primary molars. Int J Paediatr Dent 2006; 16(Suppl 1):15-23. https://doi.org/10.1111/j.1365-263X.2006.00774.x

[5] de Assuncao IV, da Costa Gde F, Borges BC. Systematic review of noninvasive treatments to arrest dentin noncavitated caries lesions. World J Clin Cases 2014; 2(5):137-41. https://doi.org/10.12998/wjcc.v2.i5.137

[6] Schwendicke F, Frencken JE, Bjorndal L, Maltz M, Manton DJ, Ricketts D, et al. Managing carious lesions: consensus recommendations on carious tissue removal. Adv Dent Res 2016; 28(2):58-67. https://doi.org/10.1177/0022034516639271

[7] Mathur VP, Dhillon JK, Logani A, Kalra G. Evaluation of indirect pulp capping using three different materials: a randomized control trial using cone-beam computed tomography. Indian J Dent Res 2016; 27(6):623-9. https://doi.org/10.4103/0970-9290.199588

[8] Gupta S, Das G. Clinical and radiographic evaluation of zinc oxide eugenol and metapex in root canal treatment of primary teeth. J Indian Soc Pedod Prev Dent 2011; 29(3):222-8. https://doi.org/10.4103/0970-4388.85829

[9] Brustolin JP, Mariath AA, Ardenghi TM, Casagrande L. Survival and factors associated with failure of pulpectomies performed in primary teeth by dental students. Braz Dent J 2017; 28(1):121-8. https://doi.org/10.1590/0103-6440201601009

[10] Wunsch PB, Kuhnen MM, Best AM, Brickhouse TH. Retrospective study of the survival rates of indirect pulp therapy versus different pulpotomy medicaments. Pediatr Dent 2016; 38(5):406-11.

[11] Melgar XC, Opdam NJM, Britto Correa M, Franzon R, Demarco FF, Araujo FB, et al. Survival and associated risk factors of selective caries removal treatments in primary teeth: a retrospective study in a high caries risk population. Caries Res 2017; 51(5):466-74. https://doi.org/10.1159/000478535

[12] American Academy of Pediatric Dentistry. Guideline on pulp therapy for primary and immature permanent teeth. Available from: https://www.aapd.org/media/Policies_Guidelines/BP_PulpTherapy.pdf. [Accessed on Dec 10, 2018].

[13] Holan G, Fuks AB. A comparison of pulpectomies using ZOE and KRI paste in primary molars: a retrospective study. Pediatr Dent 1993; 15(6):403-7.

[14] Moura-Netto C, Palo RM, Pinto LF, Mello-Moura ACV, DaltoÉ G, Wilhelmsen NSW. CT study of the performance of reciprocating and oscillatory motions in flattened root canal areas. Braz Oral Res 2014; 29(1):1-6. https://doi.org/10.1590/1807-3107BOR-2015.vol29.0006 
[15] Navit S, Jaiswal N, Khan SA, Malhotra S, Sharma A, Mukesh, et al. Antimicrobial efficacy of contemporary obturating materials used in primary teeth - an in-vitro study. J Clin Diagn Res 2016; 10(9):ZCo9-ZC12. https://doi.org/10.7860/JCDR/2016/21883.8426

[16] Coll JA, Seale NS, Vargas K, Marghalani AA, Al Shamali S, Graham L. Primary tooth vital pulp therapy: a systematic review and meta-analysis. Pediatr Dent 2017; 39(1):16-123.

[17] Rocha MJ, Cardoso M. Survival analysis of endodontically treated traumatized primary teeth. Dent Traumatol 2007; 23(6):340-7. https://doi.org/10.1111/j.1600-9657.2006.00470.x

[18] Mendoza AM, Reina JE, Garcia-Godoy F. Evolution and prognosis of necrotic primary teeth after pulpectomy. Am J Dent 2010; 23(5):265-8.

[19] Moskovitz M, Sammara E, Holan G. Success rate of root canal treatment in primary molars. J Dent 2005; 33(1):41-7. https://doi.org/10.1016/j.jdent.2004.07.009

[20] Pinky C, Shashibhushan KK, Subbareddy VV. Endodontic treatment of necrosed primary teeth using two different combinations of antibacterial drugs: an in vivo study. J Indian Soc Pedod Prev Dent 2011; 29(2):121-7. https://doi.org/10.4103/0970-4388.84684

[21] Thomas AM, Chandra S, Chandra S, Pandey RK. Elimination of infection in pulpectomized deciduous teeth: a shortterm study using iodoform paste. J Endod 1994; 20(5):233-5.

[22] Jha D, Guerrero A, Ngo T, Helfer A, Hasselgren G. Inability of laser and rotary instrumentation to eliminate root canal infection. J Am Dent Assoc 2006; 137(1):67-70. https://doi.org/10.14219/jada.archive.2006.0023

[23] Portella PD, Menoncin BLV, de Souza JF, de Menezes J, Fraiz FC, Assuncao L. Impact of molar incisor hypomineralization on quality of life in children with early mixed dentition: a hierarchical approach. Int J Paediatr Dent 2019; 29(4):496-506. https://doi.org/10.1111/ipd.12482

[24] Holan G, Needleman HL. Premature loss of primary anterior teeth due to trauma - potential short- and long-term sequelae. Dent Traumatol 2014; 30(2):100-6. https://doi.org/10.1111/edt.12081 